\title{
Schizophrenia: a delayed and uncommon presentation
}

\author{
Dushad Ram, Vinay Kumar
}

\section{Summary}

First presentations of schizophrenia after a long period of latency are not uncommon. We report an unusual case where the illness was undetected for 20 years, presented first to a non-psychiatric service and had preserved social functioning.

SL J Psychiatry 2014; 5 (1):23-24

\section{Introduction}

It is not uncommon for schizophrenia to be detected accidently when attending other physical disorders. It is also often a cause for physical injuries, probably due to a low sensitivity to pain that has been observed even in the earliest descriptions of the disease (1). We report the incidental detection of schizophrenia in a patient presenting with burns, 20 years after the onset of the illness.

\section{Case History}

A fifty-year-old, married, literate male, a farmer from a middle-income socio-economic background in an urban area presented to a general hospital with superficial burns covering $55 \%$ of the surface area of the body.

Following treatment as an in-patient in the burns unit, he was referred for psychiatric evaluation and necessary intervention as a routine procedure. On enquiry family members reported the incident as an accidental burn while the patient was at work and had no suspicions of self-infliction. The described the patient as a responsible person who regularly engaged in farming with no evidence of a recent disruption in his work pattern or behaviour.

However, the patient he revealed that he had been hearing the voices of a male which continuously commented on his actions and also commanded the patient on what to do and what not to do. He had experienced this voice for twenty years.

The patient reported that previously, he was able to ignore the voice. However, its intensity and frequency had increased over the past few months and he had been unable to ignore it when it began to command him to burn himself.

He had been to a temple to seek blessings in a bid to eliminate the voice, which was not successful. Unable to counter the instructions he was hearing, he then decided to set fire to himself believing he will then be relieved of the voices. He did so pouring kerosene oil on himself, when he was unobserved.
The patient never consulted mental health services previously; nor had he revealed his symptoms to any other person. There was no family history of mental illness. The family described the patient as a welladjusted personality in whom no unusual behaviours had been noticed previously.

The patient was commenced on risperidone $(2 \mathrm{mg}$ daily), while liaising with the surgical team treating the burn injuries. A significant improvement in the form of a marked reduction in the intensity and frequency of the voices was noted. All other investigations, including brain imaging was unremarkable. He was subsequently discharged from hospital and on follow-up, continues to report a reduction in the intensity and frequency of his symptoms.

\section{Discussion}

This case illustrates a not uncommon aspect of schizophrenia: a long period of latency before first presentation. This patient was undetected for a period of 20 years. It was also not detected by the surgical team treating the burn injuries. It is common for mental disorders to pass undetected by non-mental health professionals until severe behavioural disturbances are evident as the majority of them are not reported to physicians or other non-mental health providers (2).

However it is unusual that, despite harbouring hallucinations for a long period of time, there no behavioural changes evident in this patient and his social functioning was intact.

It has been reported that command hallucinations are common in Asian patients (3). They often contain themes of aggression, dependency, and selfpunishments (4). Compliance to such hallucinations is dependent upon associated beliefs, familiarity and emotional involvement (5).

A diminished sensitivity to pain in schizophrenia, from both behavioural pain reactivity and self-reported responses to pain has been reported (6). This is thought to be due to a different mode of pain expression than to real endogenous analgesia (7). 
This case report also highlights the need of routine screening for mental illness among patients presenting with severe burn injuries which are more prevalent in those with mental disorders, compared to the general population(8).

\section{Declaration of interest}

None declared

\section{Dushad Ram,}

Vinay Kumar

Department of Psychiatry, JSS Medical College, JSS

University, Mysore, Karnataka, India.

Corresponding author: Dushad Ram

E mail: dushadram@hotmail.com

\section{References}

1. Dworkin RH. Pain insensitivity in schizophrenia: a neglected phenomenon and some implications. Schizophr Bull. 1994; 20(2):235-48.

2. Zisook S, Byrd D, Kuck J, Jeste DV. Command hallucinations in outpatients with schizophrenia. J Clin Psychiatry. 1995 Oct;56(10):462-5.

3. Lee TM, Chong SA, Chan YH, Sathyadevan G. Command hallucinations among Asian patients with schizophrenia. Can J Psychiatry. 2004 Dec;49(12):83842. 